mado "Indian bread", é diferente do nosso porque germina em laboratório produzindo basidiocarpo ressupinado. Na Austrália, e provavelmente na India e China, ocorrem também pachymas que produzem frutificações poliporóides férteis, como por exemplo, Polyporus mylitta, espécie austraiiana, chamada "black fellow's bread" ou "native bread".

Tudo indica que todos estes fungos são relacionados e que o nosso "pão do índio" da Amazônia é uma espécie nova. Investigações adicionais são necessárias para verificar se todos eles têm a anatomia suficientemente semelhante para reuní-los em um só gênero (Pachyma). Para um estudo comparativo, torna-se necessária a obtenção dos respectivos tipos ou materiais autênticos. Nossas investigações serão concluídas neste sentido, não somente por seu interesse taxonômico como também, por seu potencial econômico, que pode ser aproveitado, se cultivado.

\section{BIBLIOGRAFIA CITADA}

BRADE, A. C.

1930 - A saporema. Bol. Mus. Nac., 6 (4): 303-juj.

ENGler, A. \& Pranth, K.

1900 - Die Natürlichen Pflanzenfamilien, 1: 171-172.

GONÇALVES, R. D.

1937 - Saporema. O Biológico, 3 (10) : 302-306.

LoCQuin, M. V.

1975 - Guide des couleurs naturelles. De Taxia Fungorum.

Maravalhas, $\mathrm{N}$.

1965 - O pão de indio. Ciência e Cultura, 17 (1) : 18-20.

Oso, B. A

1977 - Pleurotus tuber-regium from Nigeria. Mycologia, $69(2)$ : 271-279.

Weber, G. F.

1929 - The ocurrence of Tuckahoes ant Poria cocos in Florida. Mycologia, 21(3) : 113-130.

WoLF, F. A.

1922 - The fruiting stage of the tuckahoe Pachyma cocoa. Jour. Elisha Mitchell Soc., 38: 127-137, apud Weber, G. F. - The ocurrence of Tuckahoes and Poria cocos in Florida. Mycologia. 21 (3) : 113-130.

(Aceito para publicação em 03/06/78)

\title{
Baile em abelhas amazônicas
}

V. de Portugal-Araújo

Instituto Nacional de Pesquisas

da Amazônia, Manaus
A designação de "baile das abelhas" é aplicada a fenômenos comuns a Apis mellifera Linnaeus, incluindo o acasalamento e os "vôos de orientação" ou "de treinamento" de abelhas jovens em frente às suas colmeias.

No Amazonas, em Melipona e Trigona, observa-se um fenômeno próximo do "vôo de orientação ou de treinamento" de Apis mellifera que atinge um aspecto incomum em Melipona rufiventris cf. paraensis Ducke.

Verifica-se entre as abelhas amazônicas, de fins de agosto a princípios de outubro, mais especialmente em setembro, a formação de enxames de abelhas voando em frente às suas colmeias ou troncos povoados, geralmente ao meio do dia, podendo verificar-se mais tarde, mesmo que o tempo se apresente instável.
Sem qualquer sinal aparente de que o fenômeno se vai desencandear, inicia-se a saída ininterrupta de, possivelmente, todas as abeIhas adultas, incluindo abelhas jovens, que ficam voando em frente à colmeia ou tronco, num movimento suspenso, ascendente ou descendente, corpo inclinado de 20 a 40 graus e patas posteriores e médias estendidas para baixo. (Fig. 1).

Em rufiventris o número de abelhas pode atingir, aproximadamente, 5.000, formando, se o tempo se apresentar sem vento, um elipsóide de, aproximadamente, dois metros de altura por um metro e meio de diâmetro, de contornos perfeitos e completamente limitados, onde, na parte central vertical, as abelhas sobem lentamennte, descendo pela periferia ao 
chegarem ao alto, todavia, sem sairem da figura geométrica. Todas as abelhas mantêm a cabeça voltada para o centro da figura geométrica. As abelhas que, ao chegarem ao alto da figura, saem desta, escapam para cima e mais alto, para descerem rapidamente pela periferia, exteriormente, entrando pelo lado mais baixo, no rítmo do baile. (Fig. 2).

Em meliponáric, o baile, é formado aproximadamente, a um metro de altura do solo e o movimento de ar descendente, que se forma, estende-se em redor, numa área que pode atingir mais de seis metros de diâmetro. A presença de observadores não afeta a continuação do fenômeno, mesmo introduzindo a

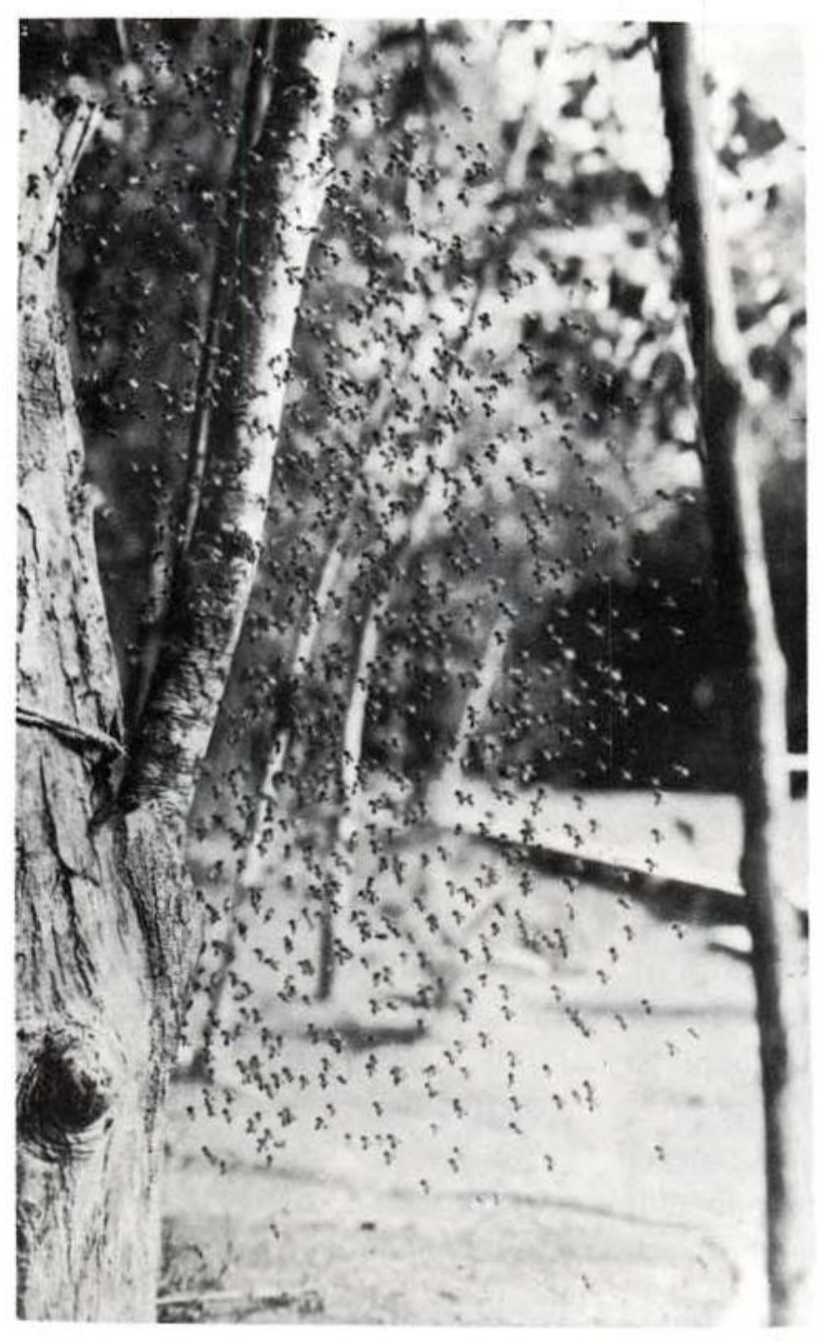

Fig. 1 - Início da formação do baile em Melipona rufiventris cf. paraensis Ducke. As abelhas mantêm-se ainda em posição de frente para tronco povoado. A entrada está localizada no terço inferior junto ao nó lateral do tronco. (Fotografia do autor). mão ou parte do corpo até ao centro da figura geométrica, estendendo-se o tempo de duração pelo espaço de uma hora.

Não estão esclarecidas as causas que levam à formação do baile das abelhas amazônicas. Em Frieseomelitta flavicornis (Fabricius) o autor teve ocasião de observar a entrada, na sua colmeia, de uma rainha apresentando o abdômen iniciando o aspecto fisiogástrico próprio de rainha madura ainda não poe-

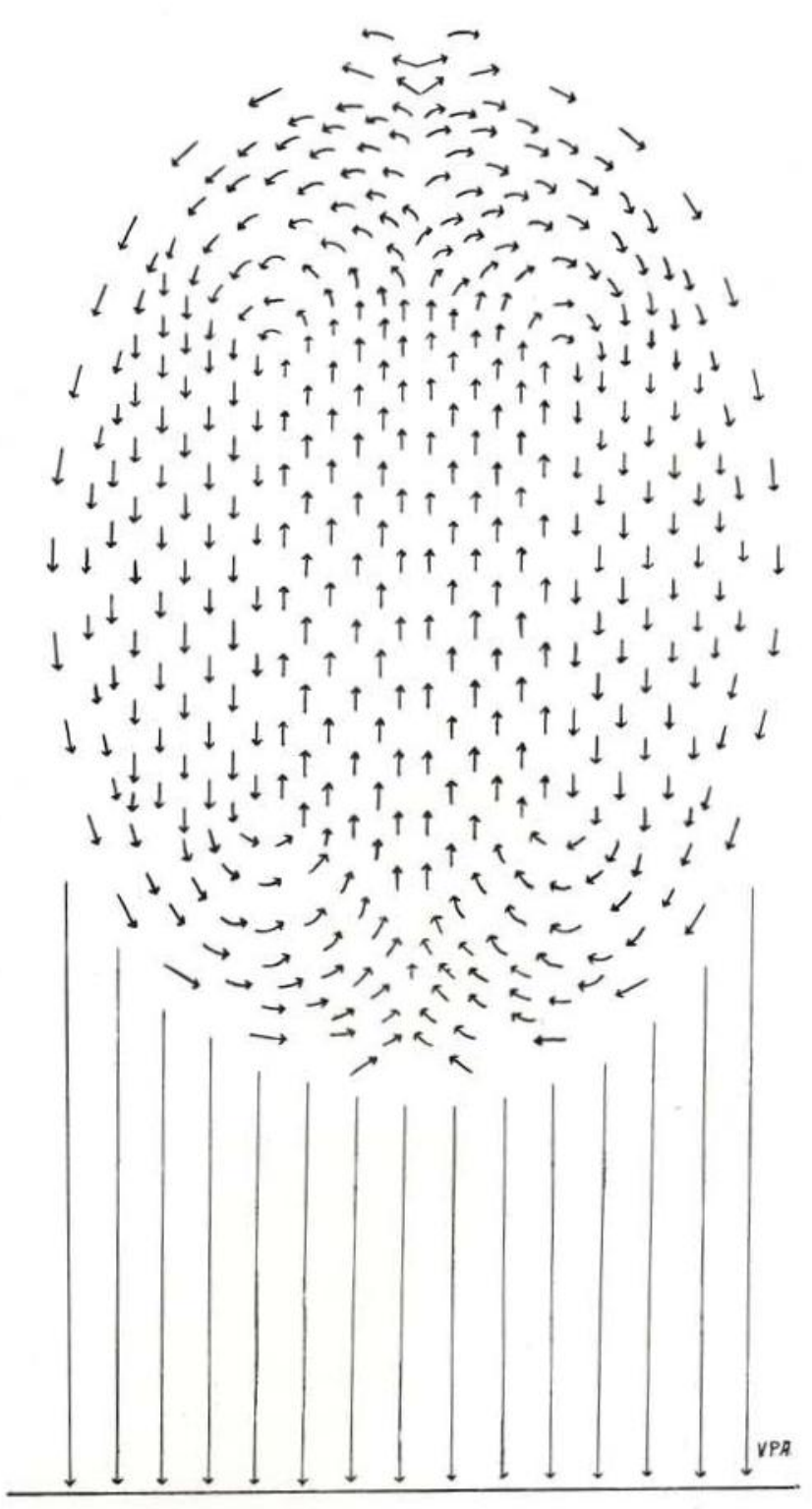

Fig. 2 - Esquema da culminância do baile em Melipona rufiventris cf. paraensis Ducke. As setas da figura geométrica mostram a direçâo do vôo das abelhas. As setas verticais inferiores mostram o movimento de ar descendente provocado pelo baile. (Desenho do autor). 
deira. Em Trigona dallatorreana Friese o autor observou a presença de grande número de machos que pousaram, sobre folhas, no final do baile e nas proxinidades da sua colmeia.

Não se pode afirmar, porém, que o fenômeno observado seja uma forma de "vôo nupcial" com a presença de um grande número de operárias, já que o fenômeno, em Melipona rufiventris foi desencandeado em várias cir- cunstâncias, inclusive, pelo alvoroço provocado por abelhas de colônias vizinhas, acabadas de serem colocadas no meliponário, que se desorientavam quanto à localização das entradas das suas colônias e, ainda, por ocasião da abertura de troncos povoados, a fim de se efetuar a transferência das abelhas para col. meias experimentais.

(Aceito para publicação em 06/06/78) 